\title{
Characterising Precipitate Evolution in Multi-component Cast Aluminium Alloys using Small-Angle X-ray Scattering
}

\author{
P. Panagos ${ }^{1,2}$, Y Wang ${ }^{1,2}$, D.G. McCartney ${ }^{2,3},{\mathrm{M} . \mathrm{Li}^{4} \text {, B. Ghaffari }}^{4}$, J.W. Zindel ${ }^{4}$, J. Miao ${ }^{5}$, S. \\ Makineni $^{5}$,J.E. Allison ${ }^{5}$, O. Shebanova ${ }^{6}$, J.D. Robson ${ }^{1}$ and Peter D. Lee ${ }^{1,2,{ }^{*}}$
}

${ }^{1}$ School of Materials, The University of Manchester, Oxford Road, Manchester, M13 9PL, UK

${ }^{2}$ Research Complex at Harwell, RAL, Didcot, OX11 0FA, UK

${ }^{3}$ Advanced Materials Group, Faculty of Engineering, University of Nottingham, University Park, Nottingham NG7 2RD, UK

${ }^{4}$ Materials Research Department, Ford Motor Company, Research and Innovation Center, MD3182, P.O Box 2053, Dearborn MI48121, USA

${ }^{5}$ Department of Materials Science and Engineering, University of Michigan, 2300 Hayward St., Ann Arbor, MI 48109, USA

${ }^{6}$ Diamond Light Source Ltd, Diamond House, Harwell Science and Innovation Campus, Didcot, Oxfordshire, OX11 0DE, UK

*Corresponding Author (e-mail address:peter.lee@manchester.ac.uk)

\begin{abstract}
Aluminium alloys can be strengthened significantly by nano-scale precipitates that restrict dislocation movement. In this study, the evolution of inhomogenously distributed trialuminide precipitates in two multi-component alloys was characterised by synchrotron small-angle Xray scattering (SAXS). The appropriate selection of reference sample and data treatment required to successfully characterise a low volume fraction of precipitates in multi-component alloys via SAXS was investigated. The resulting SAXS study allowed the analysis of statistically significant numbers of precipitates (billions) as compared to electron microscopy (hundreds). Two cast aluminium alloys with different volume fractions of $\mathrm{Al}_{3} \mathrm{Zr}_{x} \mathrm{~V}_{1-x}$ precipitates were studied. Data analysis was conducted using direct evaluation methods on SAXS spectra and the results compared with those from transmission electron microscopy (TEM). Precipitates were found to attain a spherical structure with homogeneous chemical composition. Precipitate evolution was quantified, including size, size distribution, volume fraction and number density. The results provide evidence that these multi-component alloys have a short nucleation stage, with coarsening dominating precipitate size. The coarsening rate constant was calculated and compared to similar precipitate behaviour.
\end{abstract}


Keywords: SAXS, cast aluminium alloys, precipitation, quantitative analysis, TEM, trialuminide

\section{Introduction}

For many decades, aluminium casting alloys have been widely used in the automotive industry in a variety of applications including wheels, brake components and engine parts [1]. Despite their low weight-to-volume ratio, good castability and machinability, aluminium alloys are typically limited in use to temperatures below $250^{\circ} \mathrm{C}$ [2]. Above this temperature, a significant drop in strength is observed as a result of rapid coarsening of age hardening precipitates such as those based on $\mathrm{Cu}$ or $\mathrm{Mg}$ and $\mathrm{Si}$. It has been shown that the addition of transition elements to aluminium alloys improves their high temperature properties [2-4]. Specifically, the addition of $\mathrm{Zr}$ promotes the formation of metastable cubic $\mathrm{Al}_{3} \mathrm{Zr}$ precipitates (also referred to as trialuminide dispersoids) with the $\mathrm{L}_{2}$ crystal structure. This phase is known to resist coarsening up to $\sim 400{ }^{\circ} \mathrm{C}[5]$.

The low diffusivity of $\mathrm{Zr}$ in the aluminium matrix and the low lattice misfit of the trialumininde precipitates with the matrix are the two key features promoting the good thermal stability at high temperatures [6]. A number of other low diffusivity transition elements, including Sc, Ti and $\mathrm{V}$, have been proposed, which substitute for $\mathrm{Zr}$ in the $\mathrm{Al}_{3} \mathrm{Zr}$ phase [7], in order to further increase the resistance to coarsening. Amongst them, $\mathrm{V}$ is one of the most promising candidates since it possesses the lowest diffusivity in aluminium. Furthermore, when $\mathrm{V}$ substitutes for $\mathrm{Zr}$, the lattice misfit between the precipitates and the matrix is significantly reduced $[8,9]$. The resulting precipitates are $\mathrm{Al}_{3} \mathrm{Zr}_{x} \mathrm{~V}_{1-x}$ and at temperatures below $450{ }^{\circ} \mathrm{C}$ the metastable $\mathrm{L}_{2}$ crystal structure is favoured [6]. Owing to the low solubility of both $\mathrm{Zr}$ and $\mathrm{V}$ in aluminium, $\mathrm{Al}_{3} \mathrm{Zr}_{x} \mathrm{~V}_{1-x}$ precipitates are typically nucleated in low volume fractions and are typically nonuniformly (inhomogenously) distributed due to microsegregation of $\mathrm{Zr}$ and $\mathrm{V}$ during solidification of the alloy. For these reasons, it is difficult to obtain statistically valid results on precipitate volume fraction and size distribution with traditional characterisation techniques (e.g. electron microscopy).

In the present study, we aim to (i) quantitatively characterise the precipitate evolution of two Al-6.8 wt\% Si casting alloys (also referred to as foundry alloys) containing different amounts of $\mathrm{Zr}$ and $\mathrm{V}$ by employing synchrotron small-angle X-ray scattering (SAXS) and (ii) correlate the results with a limited study by transmission electron microscopy (TEM). In SAXS, the 
sampling volume is typically more than $10^{9}$ times that of TEM, assuming a foil thickness of $100 \mathrm{~nm}$ and a field of view of $500 \times 500 \mathrm{~nm}$ for TEM and an X-ray beam diameter of $300 \mu \mathrm{m}$ with a sample thickness of $250 \mu \mathrm{m}$ for SAXS. Therefore billions of precipitates are being measured with SAXS instead of hundreds in a typical TEM foil. Thus, this technique provides quantitative and statistically reliable results including average precipitate size, volume fraction, number density and, potentially, precipitate size distribution (PSD). The application of SAXS for measuring the sizes of nanoscale precipitates in a range of metallic systems is well established, especially on binary and ternary systems [10-14]. Most previous studies of precipitation phenomena in aluminium alloys by SAXS have been conducted on precipitationhardened wrought alloys analogues, such as Al-Cu and Al-Mg-Si. A few studies have also been performed on more complex multicomponent wrought alloy systems (e.g. AA2000 and 7000 series alloys) with low volume fractions of micron-sized constituent particles (i.e. those formed from $\mathrm{Al}$ and the impurity elements $\mathrm{Fe}$ and $\mathrm{Si}$ ) [15-27]. Work on alloys that form a low volume fraction ( $\sim 1 \mathrm{vol} \%)$ of trialuminide precipitates (dispersoids) has been limited to high purity Al-Zr-Sc alloys with ppm levels of Fe and Si $[28,29]$, but not on casting alloy systems.

In the present paper, we employ SAXS to quantitatively characterise the trialuminide precipitate evolution in two complex Al-7wt\%Si casting alloys which contain a significant volume fraction of coarse (micron-sized) eutectic silicon phase as well as a low trialuminide precipitate volume fraction $(<1 \%)$. This combination of complex chemistry, multiple phases and a low volume fraction of precipitates is particularly challenging. The experimental methodology applied to this system, the primary data treatment and the reference sample selection are all discussed in detail. Quantitative results on inhomogeneously distributed precipitates, including average size, volume fraction, number density and size distribution, are reported and correlated with TEM data.

\section{Experimental Details}

\subsection{Materials, Alloy Preparation and Heat Treatments}

In this study two different alloy compositions were investigated. These are referred to as LA and HA (low and high aluminide respectively) and their compositions as determined by optical emission spectroscopy (OES) are listed in Table 1. The elements $\mathrm{Mg}$, Ti, Ni and Sr were below the detection level. The principal difference is that the HA composition has a slightly higher content of $\mathrm{Zr}$ and $\mathrm{V}$ than the LA one. Both alloys were cast at the Ford Research and Advanced 
Engineering laboratories in Dearborn, Michigan, USA. Each alloy was prepared from P1020 ( $>99.7 \%$ purity) grade of $\mathrm{Al}$ and master alloys were employed for alloy element additions. The melt was well stirred and held at $750{ }^{\circ} \mathrm{C}(\sim 60 \mathrm{~K}$ above the liquidus of the alloy) and cast into a mould to give a cylinder of dimensions $20 \mathrm{~mm}$ diameter $\times 150 \mathrm{~mm}$ long. The cooling rate of the casting was estimated to be $10 \mathrm{Ks}^{-1}$.

\section{Table 1}

LA and HA alloy compositions in wt.\% as determined by optical emission spectroscopy. The composition range of the reference alloy was specified by the supplier. Values are the mean \pm one standard deviation.

\begin{tabular}{cccccc}
\hline Alloy & Al & Si & $\mathbf{Z r}$ & $\mathbf{V}$ & $\mathbf{F e}$ \\
\hline LA & bal. & $6.77 \pm 0.08$ & $0.30 \pm 0.001$ & $0.30 \pm 0.002$ & $0.13 \pm 0.001$ \\
HA & bal. & $6.72 \pm 0.09$ & $0.37 \pm 0.001$ & $0.34 \pm 0.001$ & $0.13 \pm 0.002$ \\
Reference & bal. & $6.80 \pm 0.30$ & - & - & $0.10 \pm 0.050$ \\
\hline
\end{tabular}

Both alloys were directly aged from the as-cast condition with no prior solutionising step. Specimens of $20 \mathrm{~mm}$ diameter $\times 30 \mathrm{~mm}$ thickness were heat treated in a Carbolite CWF 1300 air furnace, the temperature of which was calibrated prior to use. The selected ageing temperature was $400{ }^{\circ} \mathrm{C}$. The LA alloy was aged for $5,10,23$ and $50 \mathrm{~h}$ whilst HA was aged for $3,5,23$ and $50 \mathrm{~h}$.

For the SAXS measurements it is necessary to have a reference sample which is free from finescale precipitation but which, in other respects, is identical to the alloys under investigation. In the present case, a cast binary Al-6.8wt\% Si alloy was employed as a reference (supplied by NewPro Foundries, Middlesex, UK). Five different specimens of dimensions $20 \times 50 \times 30 \mathrm{~mm}$ were cut from the same bar and aged at $400{ }^{\circ} \mathrm{C}$ for $3,5,10,23$ and $50 \mathrm{~h}$.

\subsection{Microstructural Characterisation}

Metallurgical examination of cast alloys using optical microscopy was undertaken using an Olympus GX51 microscope. Specimens were mounted, ground using SiC papers and polished to a $0.25 \mu \mathrm{m}$ surface finish using an alumina suspension.

TEM was undertaken in a JEOL 2100 microscope, operated at $200 \mathrm{kV}$ in scanning TEM mode (STEM), equipped with an EDAX-Ametek Octane T Optima 60 detector. Foils for TEM observations were prepared by mechanically polishing sections of specimens to a thickness of $45 \mu \mathrm{m}$ followed ion beam milling to electron transparency by using a Gatan PIPS operated at $5 \mathrm{keV}$ at $5^{\circ}$ to $-5^{\circ}$ with dual beam mode. 
Quantification of TEM images was conducted using open source software (ImageJ) [30]. Precipitate radii were measured and, assuming a perfectly spherical shape, the volume of the precipitates was then calculated. The volume fraction was also calculated as the total volume of precipitates divided by the volume of the TEM foil that contained them. In this calculation the TEM foil thickness was measured to be $120 \mathrm{~nm}$.

\subsection{Small-angle X-ray Scattering Measurements}

Specimens for the SAXS measurements of approximately $10 \times 10 \times 0.8 \mathrm{~mm}$ in size were cut from the heat treated samples using a diamond saw. These specimens were mechanically ground on both sides using progressively finer SiC papers down to P4000 grade. In order to ensure effective transmission the average sample thickness was kept constant at approximately $215 \pm 10 \mu \mathrm{m}$.

SAXS experiments were performed on the I22 beamline of the Diamond Light Source (DLS) in the UK. A monochromatic beam of wavelength $\lambda=0.67 \AA$ (i.e. of energy $18.5 \mathrm{keV}$ ) was employed. The beam size was $120 \times 350 \mu \mathrm{m}$ and samples had an average grain size of approximately $70 \mu \mathrm{m}$. This combination enabled the beam to illuminate a large number of precipitates within a number of grains. The sample to detector distance was set to $2.907 \mathrm{~m}$ and kept constant throughout the experiments. The accessible range of scattering vector, $q$, was thus 0.01 to $0.6 \AA^{-1}$. The exposure time was set to $1 \mathrm{~s}$ and the data were collected by Pilatus P3-2M detector. On every specimen 30 exposures were acquired and averaged in order to reduce noise. In total 13 different specimens (including the reference binary Al-6.8Si (wt.\%) samples) were investigated. The photon counts on the detector were converted to absolute scale by measuring a glassy carbon sample as a secondary standard for absolute intensity calibration and detector pixels were converted to the scattering vector, $q$, by measuring a reference silver behenate sample [31].

\section{SAXS Methodology and Data Analysis}

If the precipitates are not interacting (i.e. the interparticle distance is large compared to the precipitate size) then the total scattering intensity is the sum of the intensity scattered by individual precipitates [11]. In this case, and assuming a size dispersion function $f(r)$ that corresponds to the density of precipitate of size $r$, the total scattering intensity is given by[11]: 


$$
I(q)=\int_{0}^{\infty} f(r) I(q, r) \mathrm{d} r+\mathrm{B}
$$

where $q$ is the scattering vector $(q=(4 \pi \sin \theta) / \lambda)$ where the scattering angle is $2 \theta$ and $\lambda$ is the wavelength) and B is the background constant.

Our analysis was primarily based on three types of plots, namely the Guinier, Kratky and Porod plots, and the evaluations were directly carried out from the scattering data.

The precipitate size was determined by the Guinier plot $\left(\ln (I)\right.$ vs $\left.q^{2}\right)[10]$. The Guinier approximation was used, since it is a well-established analysis method in metallic systems [12, $15,17,19,26,27]$. The precipitate parameter that can be extracted is called the radius of gyration $\left(R_{\mathrm{g}}\right) . R_{\mathrm{g}}$ depends on the size distribution and has been shown to give an accurate description of the mean precipitate radius for lognormal distributions with a dispersion parameter $(s)$ close to $0.2[10,20,26]$. Here, a self-consistent method proposed by Deschamps and De Geuser [10] was followed in order to determine $R_{\mathrm{g}}$. It should be noted that the Guinier approximation is only valid in dilute solutions where the interaction between precipitates is negligible.

Another representative SAXS plot is the Kratky plot, where $I q^{2}$ is plotted versus $q$. Kratky plots are characterised by a predominant peak, where the curve reaches a maximum at $q_{\max }$. In the monodisperse case (i.e. particles of identical size), the position of this peak is related to $R_{\mathrm{g}}$ through the following relationship:

$$
R_{\mathrm{g}}=\frac{\sqrt{3}}{q_{\max }}
$$

However, in polydisperse cases this value deviates from $R_{\mathrm{g}}$ and here is referred to as $R_{\text {pseudo }}$ such that the latter is inversely related to $q_{\max }$. A comparison between $R_{\mathrm{g}}$ and $R_{\text {pseudo }}$ provides an indication of the precipitate size distribution [10].

Kratky plots can also provide an indirect estimation of the precipitate volume fraction since the latter is proportional to the integrated intensity $Q$ via the following equation: 


$$
Q=\int_{0}^{\infty} I(q) q^{2} \mathrm{~d} q=2 \pi^{2}\left(\rho_{\rho}-\rho_{\mathrm{m}}\right)^{2} f_{\mathrm{v}}\left(1-f_{\mathrm{v}}\right)
$$

where $Q$ equals the area under the curve in the Kratky plot, $\rho_{\mathrm{p}}$ and $\rho_{\mathrm{m}}$ are the scattering length densities of precipitates and matrix, respectively, and $f_{\mathrm{v}}$ is the volume fraction of precipitates. Eq. 3 is only valid for the homogeneous two-phase model with phases separated by a sharp interface.

The Porod plot $\left(I q^{4}\right.$ vs $q$ ) provides a visual indication of the chemical structure of the precipitates. For example, a uniform precipitate composition produces a different Porod profile compared to a core-shell chemical composition variation and can be identified by the overall profile of the Porod plot $[28,29,32]$. In conjunction with the $Q$ parameter we calculate Porod radius $\left(R_{\mathrm{p}}\right)$ with the following relationship:

$$
R_{\mathrm{p}}=\frac{3 Q}{\pi K_{\mathrm{p}}}
$$

where $K_{\mathrm{p}}$ is the horizontal asymptote in the Porod plot. $R_{\mathrm{p}}$ represents the radius of a sphere of surface-to-volume ratio which is equal to that of the precipitate size distribution [16].

\section{Results}

\subsection{Microstructure of the Alloys}

Optical microscopy was employed to characterise the large-scale microstructure of samples whilst TEM provided local qualitative information that can be used to support the interpretation of the SAXS measurements.

\subsubsection{Optical Microscopy}

Both alloys exhibit an equiaxed dendritic microstructure comprising $\alpha$-Al dendrites and eutectic silicon as shown in Figures $1 \mathrm{a}$ and $1 \mathrm{~b}$ for the LA and HA alloys, respectively. A small fraction of dark grey faceted particles was found to be present in both alloys (e.g. the arrowed features in Figure 1a and 1b). These were identified by energy dispersive X-ray analysis in the scanning electron microscope to be mainly $\mathrm{Zr}$-rich and are presumably primary $\mathrm{Al}_{3}(\mathrm{Zr}, \mathrm{V})$ that form directly from the melt [33] during alloy solidification as the cooling rate was $\sim 10 \mathrm{Ks}^{-1}$ 
and so was not sufficient to completely suppress the formation of this equilibrium phase with the tetragonal crystal structure.
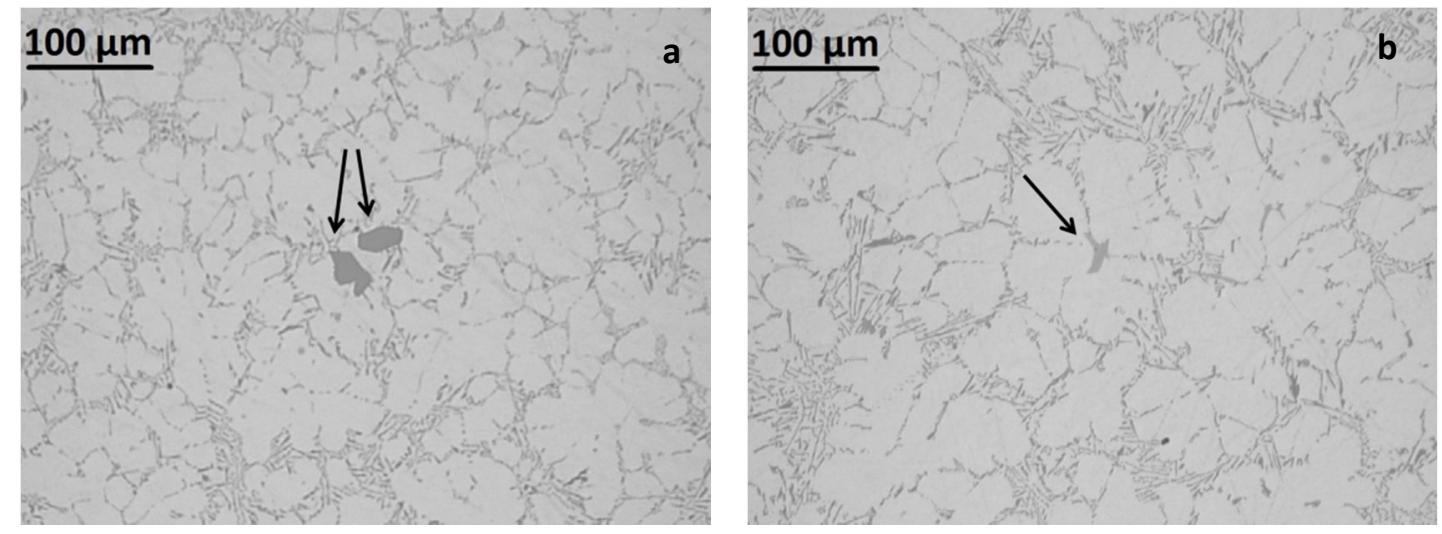

Figure 1 Optical micrographs of (a)the LA alloy and (b) the HA alloy in the as-cast condition showing $\alpha$-Al dendrites, Al-Si eutectic and a small quantity of primary $\mathrm{ZrAl}_{3}$ (arrowed)

\subsubsection{Transmission Electron Microscopy}

Scanning transmission electron microscopy (STEM) was used to examine alloys in the as-cast state and following ageing for different times with images obtained in both bright field (BF) and high angle annular dark field (HAADF) modes. In the as-cast condition, an aluminium subgrain structure was found with no evidence for precipitation as seen in the in the insert of Figure 2a (BF image of the HA alloy). Following ageing at $400{ }^{\circ} \mathrm{C}$, fine-scale spherical precipitates, typically 12 to $20 \mathrm{~nm}$ in diameter, were observed as revealed in the BF and corresponding HAADF image of Figures $2 \mathrm{a}$ and $2 \mathrm{~b}$, respectively, taken from the HA alloy following ageing for $50 \mathrm{~h}$. The precipitate distribution is clearly non-uniform and their spherical shape strongly suggests that they are the cubic $\mathrm{L}_{2}$ form of $\mathrm{Al}_{3}(\mathrm{Zr}, \mathrm{V})$ which are commonly seen in alloys containing appreciable levels of $\mathrm{Zr}$ and $\mathrm{V}[6,8,9]$. 


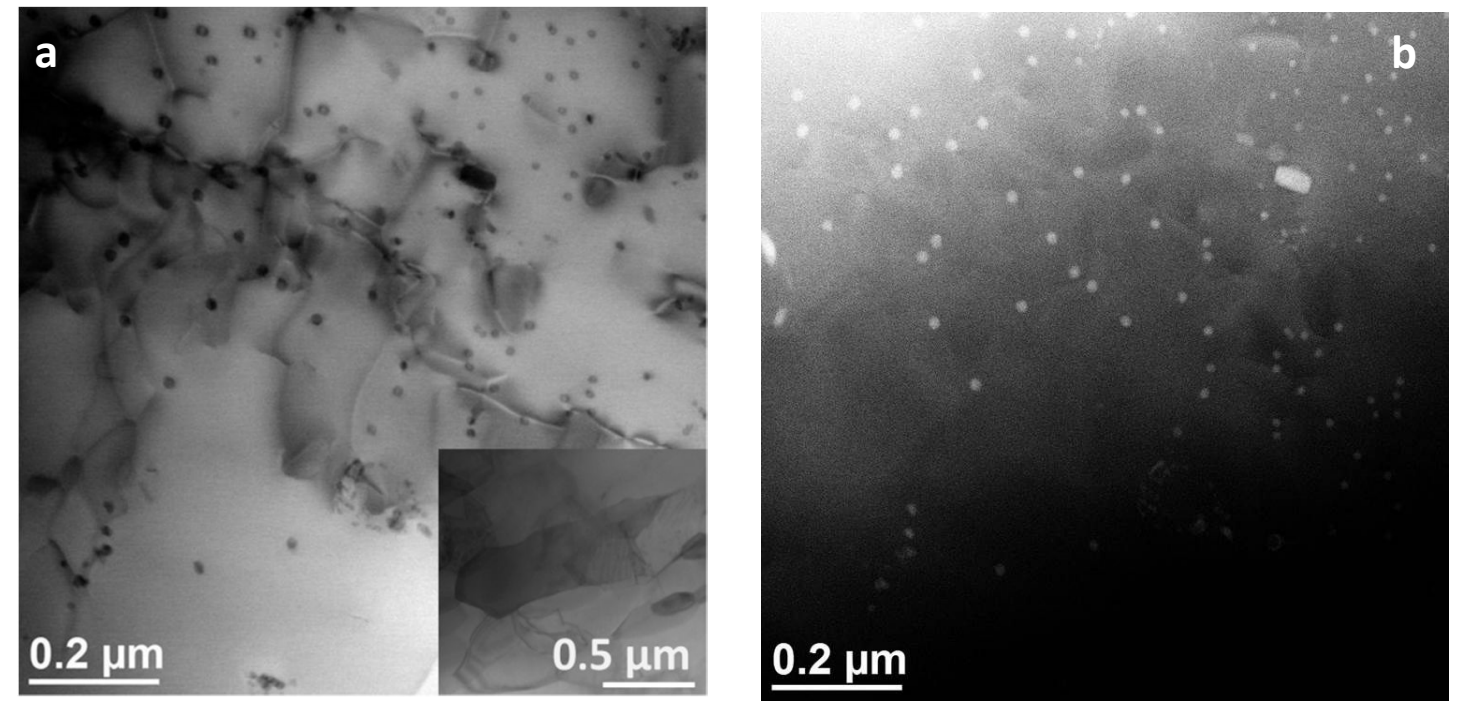

Figure 2 Bright field (a) and dark field (b) TEM images of the HA alloy aged at $400{ }^{\circ} \mathrm{C}$ for $50 \mathrm{~h}$ showing nanoscale $\mathrm{Al}_{3} \mathrm{Zr}$ precipitates in an $\alpha$-Al matrix. The inset in (a) shows a bright field image of the as-cast alloy free from precipitates.

The non-uniform nature of the precipitate distribution, combined with the small field of view in TEM, makes quantification difficult and hence it was undertaken only on the HA alloy. The main results are summarised in Table 2 which lists the mean precipitate radius $\left(R_{\mathrm{TEM}}\right)$, volume fraction and number density of precipitates for three different ageing times. The measurements reveal a monotonic increase in precipitate mean size with time. After $50 \mathrm{~h}$ at $400{ }^{\circ} \mathrm{C}$, the mean precipitate radius in the HA alloy was $7.8 \mathrm{~nm}$. However, the measured volume fraction, following ageing for different times, was found to fluctuate around $0.25 \mathrm{vol} \%$ which could be due to the difficulties in obtaining representative data from inhomogeneous precipitate distributions. In conjunction with the increase of the precipitate size, the precipitate number density continuously decreased with ageing time. Errors in Table 2 represent the standard deviation of the image analysis measurements.

\section{Table 2}

Effect of ageing time on the trialuminide precipitate radius, volume fraction and number density determined from TEM images of the HA alloy. Values are the mean \pm one standard deviation.

\begin{tabular}{ccccc}
\hline $\begin{array}{c}\text { Ageing } \\
\text { Time (h) }\end{array}$ & $\begin{array}{c}\text { Precipitates } \\
\text { Measured }\end{array}$ & $\begin{array}{c}\boldsymbol{R} \text { TEM } \\
(\mathbf{n m})\end{array}$ & $\begin{array}{c}\text { Volume } \\
\text { Fraction } \\
\text { (vol.\%) }\end{array}$ & $\begin{array}{c}\text { Number } \\
\left.\text { Density } \mathbf{( m}^{-3}\right)\end{array}$ \\
\hline $\mathbf{5}$ & 500 & $2.7 \pm 0.4$ & $0.29 \pm 0.13$ & $37.0 \pm 14.8 \times 10^{21}$ \\
$\mathbf{2 3}$ & 354 & $6.2 \pm 0.8$ & $0.19 \pm 0.08$ & $2.0 \pm 0.9 \times 10^{21}$ \\
$\mathbf{5 0}$ & 202 & $7.8 \pm 0.9$ & $0.25 \pm 0.07$ & $1.3 \pm 0.5 \times 10^{21}$ \\
\hline
\end{tabular}




\subsection{SAXS Measurements}

In every specimen tested, scattering was found to be isotropic with no evidence of perpendicular variations in the detector image. Azimuthally integrated SAXS data, in the form of one-dimensional raw scattering measurements in the $q$ range 0.01 to $0.35 \AA^{-1}$ for the Al6.8Si (wt.\%) reference alloy at five different ageing times, are shown in Figure 3. It is clear that ageing the reference alloy did not affect the SAXS curves.

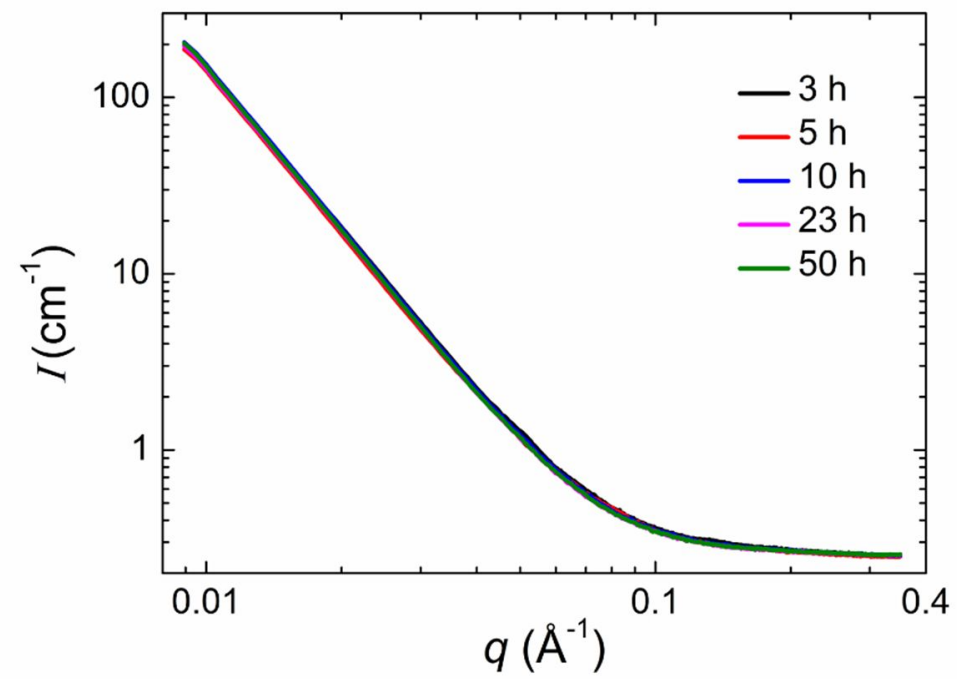

Figure 3 Plots of raw scattering intensity, I, versus scattering vector, $q$, from the binary AlSi reference alloy aged for the times shown. The scattering spectrum is unaffected by ageing.

However, when scattering data were collected from the LA and HA alloys, the one-dimensional scattering curves continually evolved with ageing time as seen in Figures $4 \mathrm{a}$ and $4 \mathrm{~b}$. It is apparent that the deviations from the reference alloy curve increased with ageing time. Figures $4 \mathrm{c}$ and $4 \mathrm{~d}$, in which the reference alloy curve has been subtracted from the LA and HA alloy curves respectively, confirm this. It is evident that there is a progressive change in the characteristic shape of the SAXS curves with ageing time in the range 0.02 to $0.1 \AA^{-1}$. In this range, every specimen features a slope change that progressively shifts towards the lower $q$ region and is accompanied by an increase in intensity. This increase in intensity presumably reflects an increasing volume fraction of precipitate and the shift to lower $q$ is indicative of an increase in precipitate size. This is observed in both the LA and HA alloys, correlating well with the TEM study. Furthermore, the average slope of the scattering data at the high $q$ region was found to be $\sim-4$ which is characteristic of precipitates that are separated from the matrix by a sharp interface [11]. 
It should be noted that the spectra in Figures $4 \mathrm{c}$ and $4 \mathrm{~d}$ have been corrected for Laue scattering and other diffuse scattering contributions using the standard methodology.
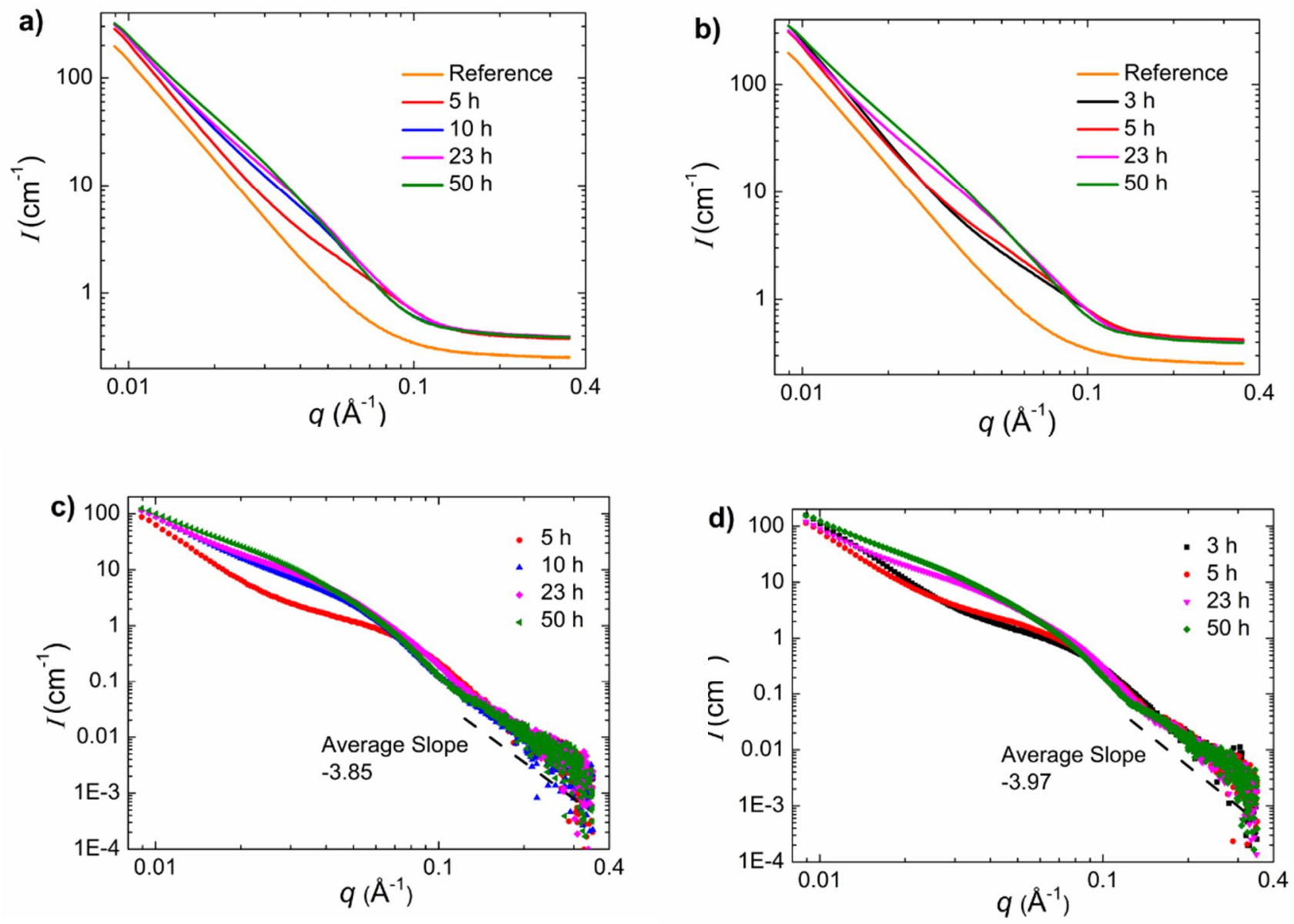

Figure 4 One dimensional SAXS patterns obtained from the LA alloy (a) and (c), and the HA alloy (b) and (d) aged at $400{ }^{\circ} \mathrm{C}$ for the times shown on the legend. (a) and (b) display the raw scattering patterns whilst (c) and (d) show the corrected scattering patterns following subtraction of the reference alloy data displayed on (a) and (b)and the Laue background. The slope at the high q Porod region is close to -4 .

A limited number of scattering spectra were also acquired outside the normal observation range. In these experiments, the accessible range of scattering vectors was from 0.0045 to 0.01 $\AA^{-1}$, so that length scales of the order of 60 to $140 \mathrm{~nm}$ could also be investigated. A representative example of the raw scattering data is shown in Figure 5 for the HA alloy aged for $5 \mathrm{~h}$. In this figure, there is no evidence of deviation from linearity i.e. there is no detectable formation of precipitates in this size range. The linear part of the scattering curve at small $q$ is of high intensity in the raw scattering curves due to scattering from the large inhomogeneities 
in the structure with sizes up to several microns, i.e. the significant volume fraction of eutectic Si phase.

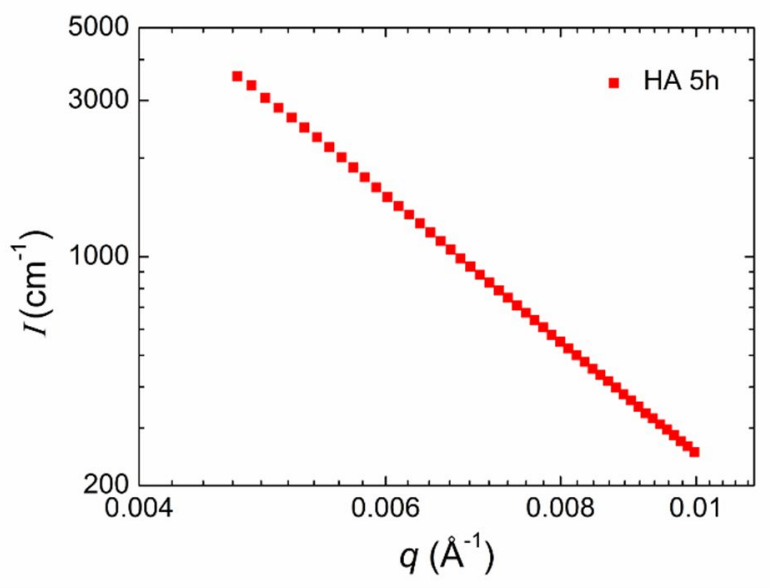

Figure 5 Representative 1-D SAXS pattern obtained from the aged HA alloy over a $q$ range below that normally observed. Note the linear behaviour with a slope $\sim-4$.

Azimuthally integrated and corrected SAXS data (with reference alloy subtracted) for the HA alloy are presented in Figure 6 for different ageing times. Figure $6 \mathrm{a}$ is the Guinier representation $\left(\ln (I)\right.$ vs $\left.q^{2}\right)$, Figure $6 \mathrm{~b}$ is the Kratky representation $\left(I q^{2}\right.$ vs $\left.q\right)$ and Figure $6 \mathrm{c}$ is the Porod representation $\left(I q^{4}\right.$ vs $q$ ). Their detailed interpretation is provided in the following section. These plots are representative of those that were also obtained from the LA alloy, which are given in Supplementary Data.

\subsection{Quantification of precipitate development}

Figure 6a shows the Guinier representation of SAXS data acquired from HA alloy. It is clear that there is a progressive change in slope with ageing time and the same trend was also found in the LA alloy. As the ageing time progresses, the slope below $0.02 \AA^{-2}$ becomes more negative as a result of precipitate growth. The Guinier radius was calculated from the slope of a linear part of the scattering curves and was determined using the self-consistent method proposed by Deschamps and De Geuser [10]. The uncertainty in $R_{\mathrm{g}}$ was determined from the error associated with the slope of the linear fit. Table 3 summarises the calculated $R_{\mathrm{g}}$ values and the associated errors for both LA and HA alloys. 

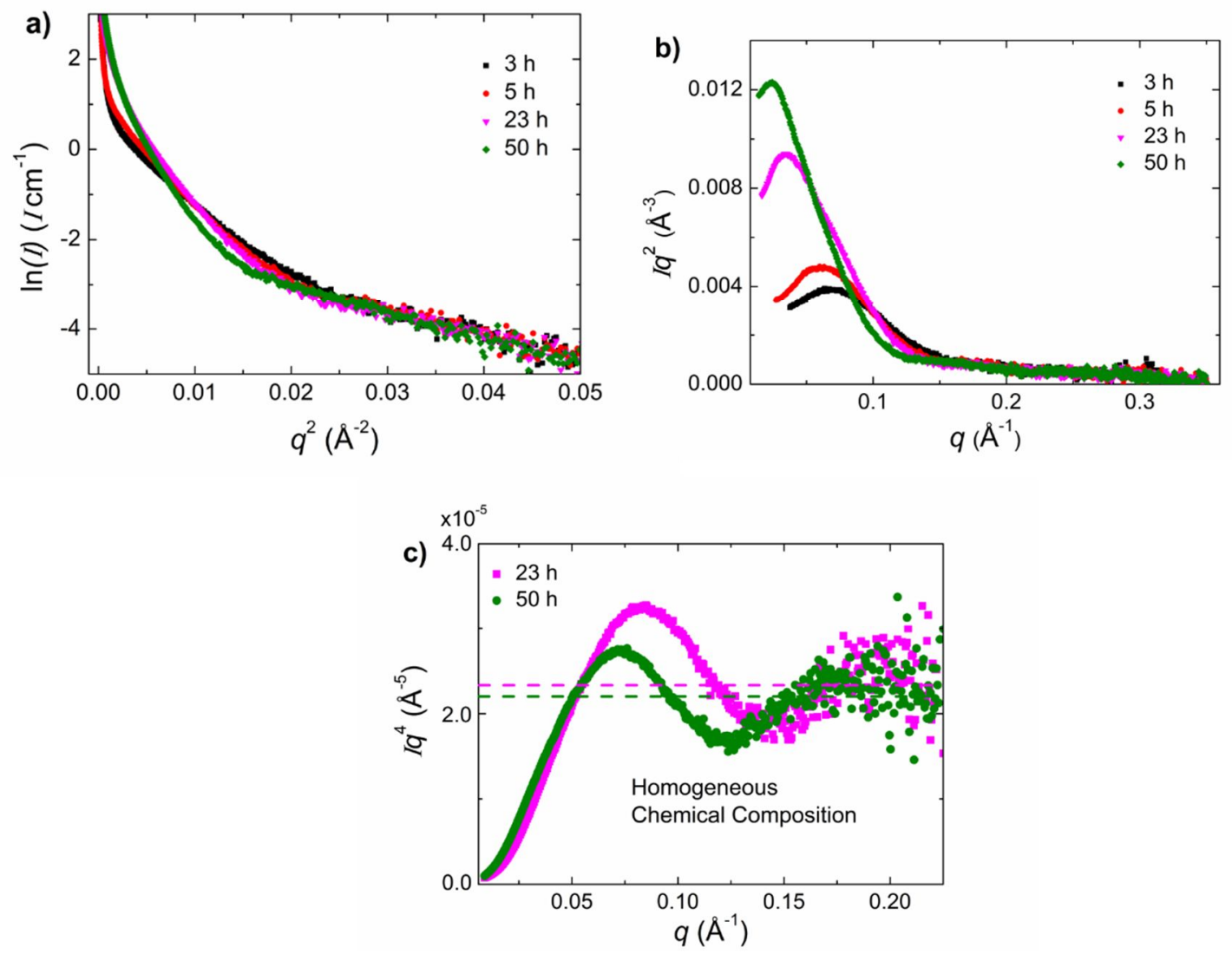

Figure 6 SAXS data for the HA alloy aged at $400{ }^{\circ} \mathrm{C}$ for the times shown on the legends. The graphs shown are: (a) the Guinier plot, (b) the Kratky plot and (c) the Porod plot.

Table 3

Effect of ageing time at $400{ }^{\circ} \mathrm{C}$ on the precipitate radii in the $L A$ and the $H A$ alloys determined from the $S A X S$ data. The Guinier radius $\left(R_{g}\right)$, pseudo-Guinier radius $\left(R_{\text {pseudo }}\right)$ and Porod radius $\left(R_{p}\right)$ are mean values \pm one standard deviation.

\begin{tabular}{ccccccc}
\hline $\begin{array}{c}\text { Ageing } \\
\text { Time (h) }\end{array}$ & \multicolumn{2}{c}{$\boldsymbol{R}_{\mathbf{g}}(\mathbf{n m})$} & \multicolumn{2}{c}{$\boldsymbol{R}_{\text {pseudo }}(\mathbf{n m})$} & \multicolumn{2}{c}{$\boldsymbol{R}_{\mathbf{p}}(\mathbf{n m})$} \\
\hline & LA & HA & LA & HA & LA & HA \\
$\mathbf{3}$ & - & $2.44+0.01$ & - & $2.47 \pm 0.05$ & - & $1.23 \pm 0.21$ \\
$\mathbf{5}$ & $3.11 \pm 0.04$ & $3.17 \pm 0.02$ & $2.71 \pm 0.05$ & $2.83 \pm 0.05$ & $1.54 \pm 0.26$ & $1.57 \pm 0.28$ \\
$\mathbf{1 0}$ & $5.32 \pm 0.06$ & - & $4.57 \pm 0.10$ & - & $2.05 \pm 0.35$ & - \\
$\mathbf{2 3}$ & $7.68 \pm 0.14$ & $6.94 \pm 0.12$ & $6.30 \pm 0.15$ & $5.04 \pm 0.15$ & $2.65 \pm 0.46$ & $2.83 \pm 0.49$ \\
$\mathbf{5 0}$ & $8.79 \pm 0.11$ & $8.82 \pm 0.12$ & $7.28 \pm 0.20$ & $6.79 \pm 0.20$ & $3.20 \pm 0.57$ & $3.29 \pm 0.58$ \\
\hline
\end{tabular}

Figure $6 \mathrm{~b}$ shows the Kratky representation for HA alloy. In this representation, the maxima in the plots allow the pseudo Guinier radius to be calculated (eqn. 2) and the area under the curves is related to the precipitate volume fraction. Two trends can be readily seen. The first one is that the main peak shifts towards smaller $q$ values which is representative of precipitate growth. 


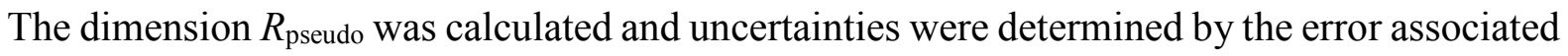
with identifying the $q_{\max }$ (Table 3). The second trend is the evolution of the area under the curve $(Q)$. As ageing time progresses $Q$ becomes larger which is an indication of an increase in the right hand side of eq. 3 . In order to calculate the volume fraction using eq. 3 we need to determine the $Q$ and the contrast parameter $\left(\rho_{\rho}-\rho_{\mathrm{m}}\right)^{2}$.

Determination of $Q$ necessitates integration between $q=0$ and $q=\infty$ which is an extremely difficult procedure as described in detail in reference [34]. In the present study, the approach used was to fit the $I q^{2}$ vs $q$ data with a lognormal distribution and extrapolate the fit to 0 and $\infty$. The lognormal distribution is described by two parameters, namely a mean and a standard deviation; the latter termed the dispersion parameter, $s$. The best lognormal fit was determined by an iterative sequence which stopped when the deviation was less than $10^{-7}$ from the previous fit. This provides a systematic and unbiased estimate of the area under the curve although there is uncertainty associated with the definition of the fitting range. Moreover, by employing a lognormal distribution the dispersion parameter, $s$, of the scattering curve was also obtained. A lognormal distribution was selected because it is reported to provide a valid approximation of the precipitate size distribution in many metallic systems [10, 20, 21].

In order to convert this integrated intensity into volume fraction, the difference in scattering length densities between the precipitate phase $\left(\rho_{\rho}\right)$ and the matrix $\left(\rho_{\mathrm{m}}\right)$ must also be calculated. We therefore need to determine their compositions. Based on energy dispersive spectroscopy (EDS) measurements in the TEM, the precipitate composition was found to be close to the stoichiometric $\mathrm{Al}_{3} \mathrm{Zr}$; the $\mathrm{V}$ content in the precipitates examined was below the detection level. However, as shown for the Al-Zr-Sc system [35], due to the difference in partition coefficients of $\mathrm{Zr}$ and $\mathrm{V}$ during solidification, the precipitate composition is expected to vary; i.e. the precipitates towards the dendrite centres are expected to contain more $\mathrm{V}$ than those towards the dendrite edges. For this reason, the volume fraction of precipitate phases was calculated for two assumed compositions, namely binary $\mathrm{Al}_{3} \mathrm{Zr}$ and $\mathrm{Al}_{3} \mathrm{Zr}_{0.8} \mathrm{~V}_{0.2}$. In the case of the matrix phase, it was assumed to be pure aluminium for the purposes of calculating the scattering length density. This is valid for two reasons. First, Si has almost the same scattering factor as $\mathrm{Al}$ (20.07 versus $22.4 \times 10^{14} \mathrm{~m}^{-2}$ ) and secondly the amount of $\mathrm{Si}$ in solid solution in the matrix will be less than 1 at $\%$. The calculated volume fractions for both assumed precipitate compositions are listed in Table 4. 
Table 4

Effect of ageing time on precipitate volume fraction in the LA and HA alloys determined from SAXS measurements. Calculations are given for two different assumptions about the precipitate composition. The error values include an absolute calibration error of $\sim \pm 15 \%$.

\begin{tabular}{|c|c|c|c|c|c|c|}
\hline \multirow{3}{*}{$\begin{array}{c}\text { Ageing } \\
\text { Time (h) }\end{array}$} & \multicolumn{6}{|c|}{ Volume fraction $(\%)$} \\
\hline & \multicolumn{3}{|c|}{ LA } & \multicolumn{3}{|c|}{ HA } \\
\hline & $\mathrm{Al}_{3} \mathrm{Zr}$ & $\mathrm{Al}_{3} \mathrm{Zr}_{0.8} \mathrm{~V}_{0.2}$ & Error & $\mathrm{Al}_{3} \mathrm{Zr}$ & $\mathrm{Al}_{3} \mathrm{Zr}_{0.8} \mathrm{~V}_{0.2}$ & Error \\
\hline 3 & - & - & - & 0.14 & 0.15 & \pm 0.02 \\
\hline 5 & 0.11 & 0.12 & \pm 0.02 & 0.16 & 0.17 & \pm 0.03 \\
\hline 10 & 0.16 & 0.17 & \pm 0.03 & - & - & - \\
\hline 23 & 0.23 & 0.24 & \pm 0.04 & 0.30 & 0.32 & \pm 0.05 \\
\hline 50 & 0.24 & 0.26 & \pm 0.04 & 0.33 & 0.36 & \pm 0.06 \\
\hline
\end{tabular}

Figure $6 \mathrm{c}$ is the Porod plot for the HA alloy. For clarity only two Porod profiles are presented; one for $23 \mathrm{~h}$ and one for $50 \mathrm{~h}$. Both curves feature a main well-defined peak and with a smaller one at the higher $q$ range. This form of Porod plot is reported to be characteristic of a spherical, polydisperse precipitate distribution which is of chemically uniform composition [28,29,32]. Every LA and HA specimens produced a similar Porod profile and the oscillations in amplitude around the smaller peak were found to decrease with increasing dispersion parameter as calculated from the lognormal distribution fit.

The Porod radius, $R_{\mathrm{p}}$, was calculated from $K_{\mathrm{p}}$ and $Q$ using eq. 4 . For consistency, $K_{\mathrm{p}}$ which is the horizontal asymptote in the Porod plot, was determined by the intercept a $I q^{4}$ vs $q^{4}$ plot [10]. The uncertainty on $R_{\mathrm{p}}$ was determined by the error associated with the volume fraction calculation and the definition of $K_{\mathrm{p}}$. In both alloys $R_{\mathrm{p}}$ was found to increase with ageing time and $R_{\mathrm{p}}$ values with the associated errors are shown in Table 3.

\section{Discussion}

SAXS and TEM provide complementary information about the precipitate evolution. In this study, unlike prior TEM investigations on similar alloys [6, 8, 36, 37], at every ageing stage, billions of precipitates were measured using SAXS. Based on both sets of measurements, it is valuable to consider the main features of the precipitate evolution and to compare them with existing knowledge of related aluminium alloys with $\mathrm{Zr}$ and/or $\mathrm{V}$ additions. 

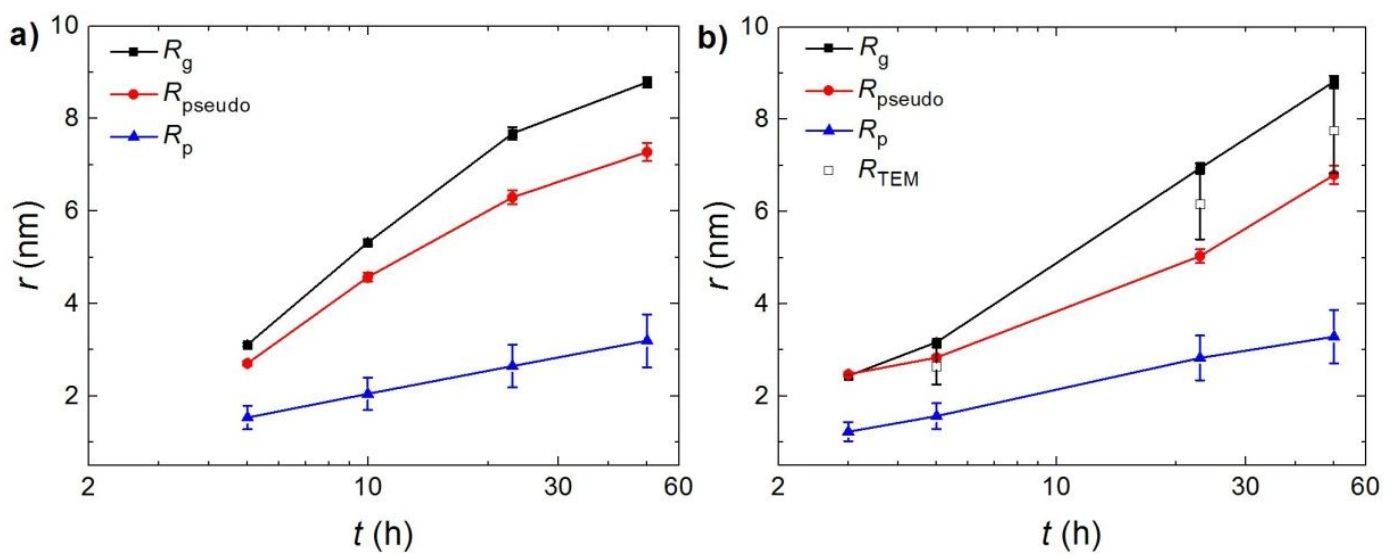

Figure 7 Effect of ageing time, $t$, on measured particle radius, $r$, for (a) the LA alloy and (b) the HA alloy. Data are shown for the SAXS measurements namely Guinier radius $\left(R_{g}\right)$, pseudo-Guinier radius $\left(R_{\text {pseudo }}\right)$ and Porod radius $\left(R_{p}\right)$ along with the radius calculated from TEM $\left(R_{T E M}\right)$ for the HA alloy.

\subsection{Analysis of Precipitate Sizes}

Figures $7 \mathrm{a}$ and $7 \mathrm{~b}$ show the values of $R_{\mathrm{g}}, R_{\mathrm{pseudo}}, R_{\mathrm{p}}$ and radius calculated from TEM measurements $\left(R_{\mathrm{TEM}}\right)$ for the alloys as a function of ageing time. In analyzing size measurements from the two techniques, it is important to consider the most appropriate of the SAXS size measurements to use when comparing with the TEM data.

Consider first the $R_{\mathrm{g}}$ measurement. The change in $R_{\mathrm{g}}$ is driven by two factors (i) a change of the physical precipitate size and (ii) a change in the dispersion of the size distribution [10]. It has been previously shown that $R_{\mathrm{g}}$ gives an accurate description of the mean precipitate radius for lognormal distributions with a dispersion parameter close to $0.2[10,20,26]$. Thus $R_{\mathrm{g}}$ and $R_{\text {TEM }}$ are both valid estimates of the mean precipitate radius when this condition is approached. $R_{\text {pseudo }}$ (eqn. 2) on the other hand is a measure of the $q$ value that contributes most to the Kratky plot but its relationship to $R_{\mathrm{g}}$ is uncertain and varies with the width of the particle size distribution (its dispersion) [10]. Finally, $R_{\mathrm{p}}$ also provides an indication of precipitate size but can be measured less accurately due to large uncertainties involved in the $Q$ and $K_{\mathrm{p}}$ calculations (eqns. 3 and 4 ) and is significantly lower than $R_{\mathrm{g}}$ when the dispersion becomes large.

Therefore, before comparing the values of $R_{\mathrm{g}}$ and $R_{\mathrm{TEM}}$, we first have to examine how the size distribution might have evolved with time. To obtain an estimate of the precipitate size distribution evolution, experimental Kratky curves were fitted with a lognormal distribution and the fitting parameters were obtained. It was found that in both alloys the dispersion parameter, $s$, of the fitting becomes larger with time. The results for HA alloy are shown in 
Figure 8. In this figure, the progressive change in the width of the normalised Kratky profiles can be attributed to a change in precipitate size distribution (PSD) as TEM provided no evidence for a change in precipitate morphology. The same trend was also found in the LA alloy where $s$ was observed to be only slightly smaller. In considering the surprisingly large width of the PSD and its evolution with time, it is important to recognise that the matrix composition is not uniform. During non-equilibrium solidification of these alloys solute segregation occurs such that dendrite cores are enriched in $\mathrm{Zr}$ and $\mathrm{V}$ and the last $\alpha$ - $\mathrm{Al}$ regions to solidify are depleted in these elements ( $\mathrm{Zr}$ and $\mathrm{V}$ both have solid-liquid partition coefficients $>1$ in contrast to $\mathrm{Si}$ which has a partition coefficient $<1$ ). During post-solidification ageing, the size and number density of the trialuminide dispersoids will exhibit spatial variations which reflect the solute distributions laid down during solidification. Such variations will then be captured by SAXS as it collects data from over 100 dendritic grains.

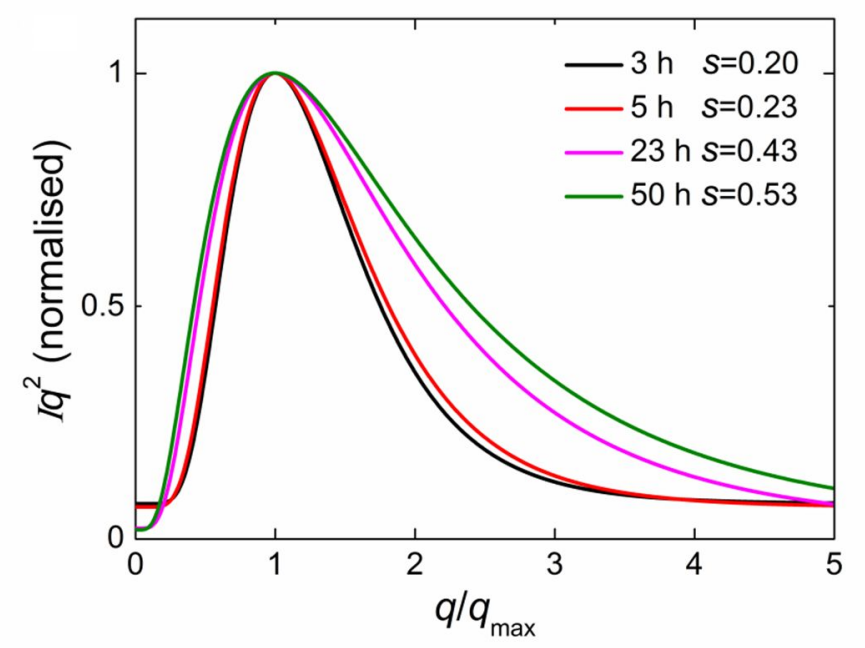

Figure 8 Normalized experimental Kratky profiles following fitting to a lognormal distribution. Plots are shown for the HA alloy aged for the times shown in the legend. The values of $s$ are the dispersion parameters of the lognormal fitting.

The deviation between $R_{\mathrm{g}}$ and $R_{\text {pseudo }}$ can also provide a relative indication of size distribution evolution. In the case of a monodisperse precipitate, these values are identical. For a polydisperse precipitate they have been shown in reference 16 to be in fair agreement up to a dispersion parameter of $\sim 0.25$. However, with a dispersion parameter of 0.3 or more, the values deviate and $R_{\mathrm{g}}$ is reported to be larger than $R_{\text {pseudo }}$ [10]. In the present work, their deviation as 
a function of time (Figure 7) also supports the size distribution evolution which was predicted from the normalised Kratky curves. At 3 and $5 \mathrm{~h}$ ageing time, $R_{\mathrm{g}}$ and $R_{\text {pseudo }}$ values are close whereas at longer ageing times $R_{\mathrm{g}}$ and $R_{\text {pseudo }}$ deviate suggesting an increase in the width of the size distribution. The evolution of $R_{\mathrm{p}}$ with ageing time in relation to $R_{\mathrm{g}}$ (Figure 7) is also in agreement with the suggestion of an increasing dispersion of the particle size distribution as it increasingly deviates from $R_{\mathrm{g}}$ and $R_{\text {pseudo. }}$

Therefore, overall, $R_{\mathrm{g}}$, provides the best SAXS size parameter for comparison with TEM measurements with the caveat that it is most likely to be closer to a mean radius at the beginning of ageing than towards the end due to an increasing dispersion of the precipitate size distribution. It is seen in Figure 7(b) that there is indeed very reasonable agreement between the TEM and the SAXS measurements for HA samples. It should be noted that the $R_{\text {TEM values }}$ may be subjected to biases related to the wide size distribution of the trialuminides which is associated with their heterogeneous distribution arising from solidification microsegregation of $\mathrm{Zr} / \mathrm{V}$. When compared with previous studies on Al-Zr alloys, the precipitate radii at $50 \mathrm{~h}$ from SAXS data ( $R g$ values) are in reasonable agreement with values reported for arc-melted alloys but differ from those that have been melt-spun [36-38].

Finally, the coarsening rate constant of the trialuminide precipitates was obtained using the classical Lifshitz, Slyozov and Wagner (LSW) theory and was calculated from the $R_{\mathrm{g}}$ measurements (Figures $7 \mathrm{a}$ and $7 \mathrm{~b}$ ). The calculated values are $1.41 \times 10^{-26} \mathrm{~m}^{3} \mathrm{~h}^{-1}$ and $1.45 \times 10^{-26}$ $\mathrm{m}^{3} \mathrm{~h}^{-1}$ for LA and HA alloy, respectively at $400{ }^{\circ} \mathrm{C}$ in the time scale 5 to $50 \mathrm{~h}$. Both values are in broad agreement with values reported for the ternary Al-Zr-V alloy system [6, 8, 9, 36] although at the higher end of the range. However, additions of Si were shown to accelerate the precipitation kinetics in $\mathrm{Zr}$ containing alloys [39-42] and, as stated earlier, $R_{\mathrm{g}}$ measurements are partially driven by the evolution of the precipitate size distribution. Hence, although they provide a valid estimate, these values should be considered as an upper limit of the coarsening rate constant.

\subsection{Main Features of the Precipitate Volume Fraction and Number Density Evolution}

In order to gain a better understanding of the precipitate evolution we compared the volume fraction and number density results for both alloys. Based on the Lever Rule, and assuming that the precipitate volume fraction is dictated by the $\mathrm{Zr}$ concentration, the calculated equilibrium fractions of $\mathrm{Al}_{3} \mathrm{Zr}$ are approximately 0.4 vol.\% and 0.5 vol.\% for LA and HA alloy, 
respectively. As $\mathrm{V}$ could not be detected in the precipitates it is assumed that it remains in solution in the aluminium matrix phase.

Figure 9a shows the precipitate volume fractions in both alloys assuming either an $\mathrm{Al}_{3} \mathrm{Zr}$ or an $\mathrm{Al}_{3} \mathrm{Zr}_{0.8} \mathrm{~V}_{0.2}$ composition (according to eqn 3 the calculated volume fraction depends on the square of the difference in scattering length density between precipitate and matrix). As expected, the HA alloy has a larger volume fraction compared to the LA. However, the volume fraction in both alloys is somewhat lower than the Lever rule prediction. This is attributed to the reduction of the available solute, as a result of the precipitation of primary aluminide during solidification (Figures 1a and 1b). Figure 9a also shows that in both alloys the volume fraction continuously increases with time and the increase remains rapid up to $23 \mathrm{~h}$. The highest value does not exceed 0.36 vol. $\%$ in the HA alloy while the lowest is 0.11 vol. $\%$ in the LA aged for $5 \mathrm{~h}$. The volume fraction ratio of the alloys was found to be $\sim 1.3$ for 5,23 and $50 \mathrm{~h}$ which agrees well with the ratio of $\mathrm{Zr}$ solute in the alloys (1.23). As noted before, the calculation of the precipitate volume fraction using TEM is subjected to biases and large scatter related to the heterogeneous distribution of precipitates in the dendritic microstructure. However, the volume fraction values calculated from TEM (Table 2) are in broad agreement with SAXS results.

a)

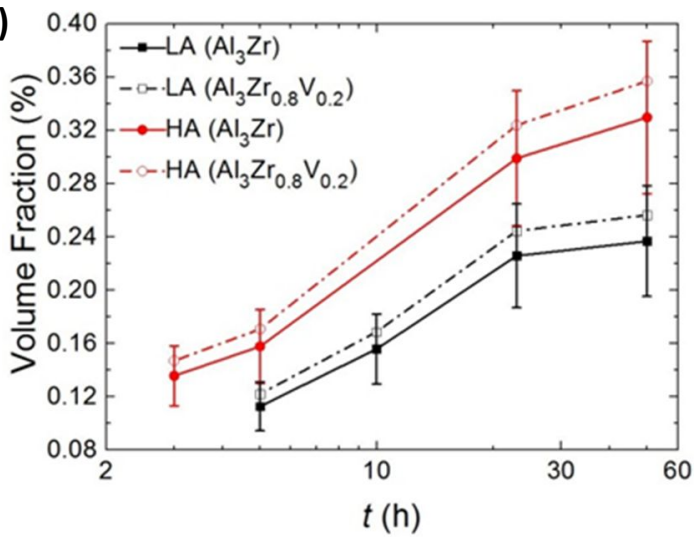

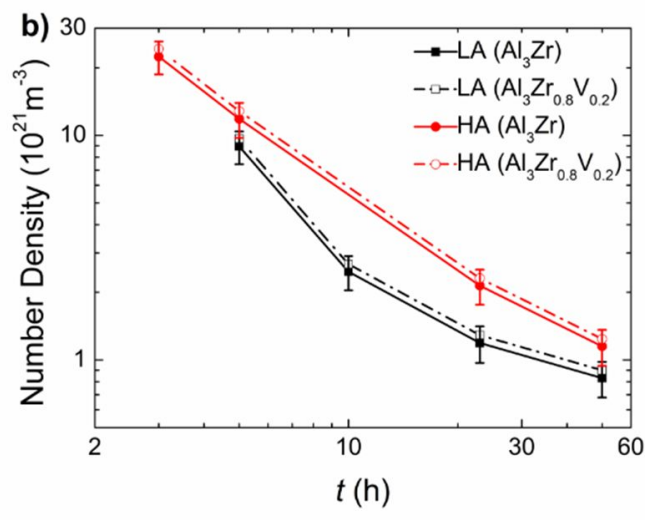

Figure 9 Effect of ageing time, $t$, at $400{ }^{\circ} \mathrm{C}$ on (a) volume fraction and ( b) number density of trialuminide precipitates in the LA and the HA alloys from SAXS measurements. Calculations were performed for two different assumptions about precipitate composition.

The number density of precipitates was determined by assuming a perfectly spherical shape and using the following relationship:

$$
N=\frac{f_{\mathrm{v}}}{\frac{4}{3} \pi R_{\mathrm{g}}^{3}}
$$


where $f_{\mathrm{v}}$ is the precipitate volume fraction and $R_{\mathrm{g}}$ the radius of gyration obtained by the Guinier plot.

Figure $9 \mathrm{~b}$, plotted on a log-log scale, shows that in the HA alloy the number density closely follows a $t^{-1}$ relationship as expected from the LSW analysis. However, whilst the LA alloy also shows a decrease in number density with ageing time, agreement with the LSW model is not as good. During the nucleation stage of precipitation when the driving force is high, small precipitates are expected to form giving a high number density which quickly peaks. It would appear that this stage was not captured in the present experiments where the minimum ageing time studies were $5 \mathrm{~h}$. In the present study, despite the significant increase in the volume fraction, the number density declines continuously. This behaviour might suggest an overlap in the growth and coarsening regimes of precipitation. Nevertheless, high number densities were recorded with the highest value exceeding $2 \times 10^{22} \mathrm{~m}^{-3}$ in the HA alloy aged for $3 \mathrm{~h}$. TEM number density results (Table 2), based on the measurement of many fewer precipitates, show acceptable agreement with SAXS measurements of typically more than $10^{11}$ precipitates.

\section{Summary and Conclusions}

- The combination of transmission electron microscopy (TEM) and small angle X-ray scattering (SAXS) was successfully employed to quantitatively characterise the evolution of trialuminide precipitates in two cast Al-7wt.\% Si alloys containing different additions of $\mathrm{Zr}$ and $\mathrm{V}$ which were aged at $400{ }^{\circ} \mathrm{C}$. The results confirm that SAXS can be employed to investigate this phenomenon even at low $(<0.5 \%)$ volume fractions of precipitate providing an appropriate standard is selected.

- TEM confirmed the presence of an inhomogenous distribution of spherical metastable cubic $\mathrm{L}_{2}$ precipitates of the type $\mathrm{Al}_{3} \mathrm{Zr}$ in both alloys. There was no evidence for incorporation of $\mathrm{V}$ into those precipitates examined in these alloys which were conventionally cast and aged at $400{ }^{\circ} \mathrm{C}$.

- Using model-independent and self-consistent methods, the precipitate evolution was characterized using synchrotron SAXS. At each ageing stage, billions of precipitates were measured as compared with several hundred in TEM analysis.

- The mean precipitate size was determined from the SAXS data in terms of a Guinier radius which increased with ageing time from $\sim 3 \mathrm{~nm}$ after $5 \mathrm{~h}$ ageing to $\sim 9 \mathrm{~nm}$ after $50 \mathrm{~h}$ ageing. These values are consistent with the TEM measurements. 
- The precipitate volume fraction, measured from the SAXS data, increased with ageing time in both alloys; reaching $\sim 0.25 \mathrm{vol} \%$ in the LA alloy and $\sim 0.35 \mathrm{vol} \%$ in the HA alloy after $50 \mathrm{~h}$ at $400{ }^{\circ} \mathrm{C}$. There is reasonable agreement with the much more limited volume fraction measurements from TEM. The precipitate number density decreased continuously with ageing time in both alloys suggesting that the stages of precipitate growth and coarsening overlap during the time period studied and that the investigation did not capture the initial nucleation stage.

- The coarsening rate was calculated as $1.41 \times 10^{-26}$ and $1.45 \times 10^{-26} \mathrm{~m}^{3} \mathrm{~h}^{-1}$ for LA and HA alloy, respectively, at $400{ }^{\circ} \mathrm{C}$ in the time scale 5 to $50 \mathrm{~h}$.

\section{Acknowledgements}

This work was made possible by the facilities and support provided by the Research Complex at Harwell, funded in part by the EPSRC (EP/I02249X/1, EP/K007734/1 and EP/M009688/1). This research was also supported by the Ford Motor Company University Research Program. We acknowledge the Diamond-Manchester Collaboration for the time granted on the I22 beamline at Diamond Light Source under proposal SM13238-1. The support of the I22 beamline staff during the experiments is greatly appreciated. Data statement: representative data from the experiments is presented in the graphs in this manuscript and the supplementary data.

\section{References}

1. W.S. Miller, L. Zhuang, J. Bottema, A.J. Wittebrood, P.D. Smet, A. Haszler, A. Vieregge, Recent development in aluminium alloys for the automotive industry, Materials Science and Engineering A, 280 (2000) 37-49.

2. J. Hernandez-Sandoval, G.H. Garza-Elizondo, A.M. Samuel, S. Valtiierra, F.H. Samuel, The ambient and high temperature deformation behavior of $\mathrm{Al}-\mathrm{Si}-\mathrm{Cu}-$ Mg alloy with minor Ti, Zr, Ni additions, Materials \& Design, 58 (2014) 89-101.

3. Z.-h. Jia, J.-P. Couzinié, N. Cherdoudi, I. Guillot, L. Arnberg, P. Asholt, S. Brusethaug, B. Barlas, D. Massinon, Precipitation behaviour of $\mathrm{Al}_{3} \mathrm{Zr}$ precipitate in $\mathrm{Al}-\mathrm{Cu}-\mathrm{Zr}$ and $\mathrm{Al}-\mathrm{Cu}-\mathrm{Zr}-\mathrm{Ti}-\mathrm{V}$ alloys, Transactions of Nonferrous Metals Society of China, 22 (2012) 1860-1865.

4. P. Sepehrband, R. Mahmudi, F. Khomamizadeh, Effect of $\mathrm{Zr}$ addition on the aging behavior of A319 aluminum cast alloy, Scripta Materialia, 52 (2005) 253257. 
5. K.E. Knipling, R.A. Karnesky, C.P. Lee, D.C. Dunand, D.N. Seidman, Precipitation evolution in Al-0.1Sc, Al-0.1Zr and Al-0.1Sc-0.1Zr (at.\%) alloys during isochronal aging, Acta Materialia, 58 (2010) 5184-5195.

6. C.Y. Chen, M.E. Fine, J.R. Weertman, R.E. Lewis, Coarsening behavior of $\mathrm{L}_{2}$ structured $\mathrm{Al}_{3}\left(\mathrm{Zr}_{\mathrm{x}} \mathrm{V}_{1-\mathrm{x}}\right)$ precipitates in rapidly solidified $\mathrm{Al}-\mathrm{Zr}-\mathrm{V}$ alloy, Scripta Metallugica, 21 (1987) 1003-1008.

7. S.Z. Han, S.I. Park, J. Huh, Z. Lee, H.M. Lee, Lattice matching of $\mathrm{DO}_{23}$ and $\mathrm{DO}_{22}$ phases in Al-6at.\% (Ti, V, Zr) systems, Materials Science and Engineering A, 230 (1997) 100-106.

8. Y.C. Chen, M.E. Fine, J.R. Weertman, Microstructural evolution and mechanical properties of rapidly solidified Al-Zr-V alloys at high temperatures, Acta metall. mater, 38 (1990) 771-780.

9. H. Lee, S.Z. Han, H.M. Lee, Z.-h. Lee, Coarsening behavior of $\mathrm{LI}_{2}$ precipitates in melt-spun Al-Ti-V-Zr alloys, Materials Science and Engineering A, 163 (1993) 81-90.

10. A.Deschamps, F. De Geuser, On the validity of simple precipitate size measurements by small-angle scattering in metallic systems, Journal of Applied Crystallography, 44 (2011) 343-352.

11. F. De Geuser, A. Deschamps, Precipitate characterisation in metallic systems by small-angle X-ray or neutron scattering, Comptes Rendus Physique, 13 (2012) 246-256.

12. E.G. Dere, H. Sharma, R.M. Huizenga, G. Portale, W. Bras, V. Bliznuk, J. Sietsma, S.E. Offerman, Formation of $(\mathrm{Fe}, \mathrm{Cr})$ carbides and dislocation structures in low-chromium steel studied in situ using synchrotron radiation, Journal of Applied Crystallography, 46 (2012) 181-192.

13. J.M. Rosalie, B.R. Pauw, Form-free size distributions from complementary stereological TEM/SAXS on precipitates in a Mg-Zn alloy, Acta Materialia, 66 (2014) 150-162.

14. A. Rashkova, W. Prantl, R. Görgl, J. Keckes, S. Cohen, M. Bamberger, G. Dehm, Precipitation processes in a Mg-Zn-Sn alloy studied by TEM and SAXS, Materials Science and Engineering A, 494 (2008) 158-165.

15. C.S. Tsao, U.S. Jeng, C.Y. Chen, T.Y. Kuo, Small-angle X-ray scattering study of nanostructure evolution of $\beta^{\prime \prime}$ precipitates in Al-Mg-Si alloy, Scripta Materialia, 53 (2005) 1241-1245.

16. C.S. Tsao, C.Y. Chen, U.S. Jeng, T.Y. Kuo, Precipitation kinetics and transformation of metastable phases in Al-Mg-Si alloys, Acta Materialia, 54 (2006) 4621-4631.

17. P. Schloth, A. Menzel, J.L. Fife, J.N. Wagner, H. Van Swygenhoven, J.M. Drezet, Early cluster formation during rapid cooling of an $\mathrm{Al}-\mathrm{Cu}-\mathrm{Mg}$ alloy: In situ small-angle X-ray scattering, Scripta Materialia, 108 (2015) 56-59.

18. C. Genevois, A. Deschamps, A. Denquin, B. Doisneaucottignies, Quantitative investigation of precipitation and mechanical behaviour for AA2024 friction stir welds, Acta Materialia, 53 (2005) 2447-2458.

19. M. Dumont, A. Steuwer, A. Deschamps, M. Peel, P. Withers, Microstructure mapping in friction stir welds of 7449 aluminium alloy using SAXS, Acta Materialia, 54 (2006) 4793-4801.

20. A.Deschamps, F. De Geuser, Z. Horita, S. Lee, G. Renou, Precipitation kinetics in a severely plastically deformed 7075 aluminium alloy, Acta Materialia, 66 (2014) 105-117. 
21. T. Marlaud, A. Deschamps, F. Bley, W. Lefebvre, B. Baroux, Influence of alloy composition and heat treatment on precipitate composition in $\mathrm{Al}-\mathrm{Zn}-\mathrm{Mg}-\mathrm{Cu}$ alloys, Acta Materialia, 58 (2010) 248-260.

22. T. Marlaud, A. Deschamps, F. Bley, W. Lefebvre, B. Baroux, Evolution of precipitate microstructures during the retrogression and re-ageing heat treatment of an Al-Zn-Mg-Cu alloy, Acta Materialia, 58 (2010) 4814-4826.

23. C.-S. Tsao, E.-W. Huang, M.-H. Wen, T.-Y. Kuo, S.-L. Jeng, U.-S. Jeng, Y.-S. Sun, Phase transformation and precipitation of an $\mathrm{Al}-\mathrm{Cu}$ alloy during nonisothermal heating studied by in situ small-angle and wide-angle scattering, Journal of Alloys and Compounds, 579 (2013) 138-146.

24. J.C. Werenskiold, A. Deschamps, Y. Bre, Characterization and modeling of precipitation kinetics in an $\mathrm{Al}-\mathrm{Zn}-\mathrm{Mg}$ alloy, Materials Science and Engineering A, 293 (2000) 267-274.

25. M. Dumont, W. Lefebvre, B. Doisneau-Cottignies, A. Deschamps, Characterisation of the composition and volume fraction of $\eta^{\prime}$ and $\eta$ precipitates in an $\mathrm{Al}-\mathrm{Zn}-\mathrm{Mg}$ alloy by a combination of atom probe, small-angle X-ray scattering and transmission electron microscopy, Acta Materialia, 53 (2005) 2881-2892.

26. A. Deschamps, T.J. Bastow, F. de Geuser, a.J. Hill, C.R. Hutchinson, In situ evaluation of the microstructure evolution during rapid hardening of an $\mathrm{Al}-$ 2.5Cu-1.5Mg (wt.\%) alloy, Acta Materialia, 59 (2011) 2918-2927.

27. E.W. Huang, C.-S. Tsao, M.-H. Wen, T.-Y. Kuo, S.-Y. Tu, B.-W. Wu, C.-J. Su, U.S. Jeng, Resolution of structural transformation of intermediates in $\mathrm{Al}-\mathrm{Cu}$ alloys during non-isothermal precipitation, Journal of Materials Research, 29 (2014) 874-879.

28. A. Deschamps, L. Lae, P. Guyot, In situ small-angle scattering study of the precipitation kinetics in an Al-Zr-Sc alloy, Acta Materialia, 55 (2007) 27752783.

29. E. Clouet, L. Laé, T. Épicier, W. Lefebvre, M. Nastar, A. Deschamps, Complex precipitation pathways in multicomponent alloys, Nature Materials, 5 (2006) 482488.

30. C.A. Schneider, W.S. Rasband, K.W. Eliceiri, NIH Image to ImageJ: 25 years of image analysis, Nat Meth, 9 (2012) 671-675.

31. F. Zhang, J. Ilavsky, G.G. Long, J.P.G. Quintana, A.J. Allen, P.R. Jemian, Glassy Carbon as an Absolute Intensity Calibration Standard for Small-Angle Scattering, Metallurgical and Materials Transactions A, 41 (2009) 1151-1158.

32. Ph. A. Dubey, B. Schonfeld, G. Kostorz, Shape and internal structure of GuinierPreston zones in Al-Ag, Acta metall. mater, 39 (1991) 1161-1170.

33. D.G. Eskin, Effect of melt overheating on primary solidification in aluminium alloys, Zeitschrift für Metallkunde, 87 (1996) 295-299.

34. A. Deschamps, F. de Geuser, Quantitative Characterization of Precipitate Microstructures in Metallic Alloys Using Small-Angle Scattering, Metallurgical and Materials Transactions A, 44 (2012) 77-86.

35. J.D. Robson, A new model for prediction of dispersoid precipitation in aluminium alloys containing zirconium and scandium, Acta Materialia, 52 (2004) 1409-1421.

36. M.S. Zedalis, M.E. Fine, Precipitation and Ostwald ripening in dilute AI base-ZrV alloys, Metallurgical and Materials Transactions A, 17 (1986) 2187-2198.

37. W.-W. Park, Alloy designing and characterization of rapidly solidified Al-Zr(-V) base alloys, Materials \& Design, 17 (1996) 85-88. 
38. K.E. Knipling, D.C. Dunand, D.N. Seidman, Precipitation evolution in Al-Zr and $\mathrm{Al}-\mathrm{Zr}-\mathrm{Ti}$ alloys during isothermal aging at $375-425^{\circ} \mathrm{C}$, Acta Materialia, 56 (2008) 114-127.

39. T. Gao, A. Ceguerra, A. Breen, X. Liu, Y. Wu, S. Ringer, Precipitation behaviors of cubic and tetragonal $\mathrm{Zr}-$ rich phase in $\mathrm{Al}-(\mathrm{Si}-) \mathrm{Zr}$ alloys, Journal of Alloys and Compounds, 674 (2016) 125-130.

40. C. Booth-Morrison, Z. Mao, M. Diaz, D.C. Dunand, C. Wolverton, D.N. Seidman, Role of silicon in accelerating the nucleation of $\mathrm{Al}_{3}(\mathrm{Sc}, \mathrm{Zr})$ precipitates in dilute Al-Sc-Zr alloys, Acta Materialia, 60 (2012) 4740-4752.

41. S. Hori, S. Saji, Y. Higaki, Effects of Fe and Si on the aging process of subperitectic Al-Zr alloys, J. Japan Inst. Light Metals, 25 (1975) 247-252.

42. T. Ikeda, T. Tachikaw, M. Ikeda, S.-Y. Komatsu, Precipitation and dissolution of solute atoms in high purity and commercial Al-Zr alloys, Mater. Trans, 38 (1997) 413-419. 